\title{
KFKI-1980-125
}

A, ZAWADOWSKI

\section{KONDO LIKE STATE IN A SIMPLE MODEL FOR METALLIC GLASSES}

\section{Hungarian Academy of Sciences CENTRAL RESEARCH INSTITUTE FOR PHYSICS}


KFKI-1980-125

\title{
KONDO LIKE STATE IN A SIMPLE MODEL FOR METALLIC GLASSES
}

\author{
A. Zawadowski \\ Department of Physics \\ University of Illinois at Urbana-Champaign \\ Urbana, IL $61801 * * *$
}

To be published in Phys. Rev. Letters

(Corrected version)

HU ISSN 03685330

ISBN $9633 \quad 371 \quad 771 X$

* Permanent address: Central Research Institute for Physics, Budapest

P.0.B. 49, Hungary 1525

** Supported by NSF Grant No. DMR78-21068 


\section{ABSTRACT}

Simple model is constructed for the tunneling two level systems interacting with the conduction electrons in metallic glasses. The coupling constants do not commute in the momentum space. Scaling theory shows a strong similarity with the antiferromagnetic Kondo effect and it is shown that at low temperature a bound state is formed in which the motion of the tunneling atom and the angular dependence of the screening electron cloud varying in time are strongly correlated.

\section{АННОТАЦИЯ}

Сконструирована простая модель для описания туннелирования системы двух уровней, взаимодействующих с электронами проводимости в аморфных металлах. Константы связи в импульсном пространстве не коммутируют. Теория скэйлинга показывает сильное сходство с антиферромагнитным эффектом Кондо, и показано, что при низких температурах образуется связанное состояние, в котором движение туннелирующего атома сильно коррелировано с угловой зависимостью экранирующего электронного облака, меняющейся во времени.

\section{KIVONAT}

Fémüvegekben a vezetési elektronokkal kölcsönható alagutazó két nivós rendszerre egy egyszerü modellt javasolunk, amelyben a csatolási állandók az impulzustérben nem felcserélhetôk. A skálázás elmélete nagyon hasonlit az antiferromágneses Kondo effektusra, és alacsony hômérsékletekre megmutatjuk, hogy egy kötött állapot keletkezik, amelyben az alagutazó atom mozgása és a leárnyékolási felhô szögfüggése erôs korrelációban van. 
Recently great attention has been, attracted by tunneling two level systems (TLS) $\stackrel{1,2 /}{1}$ in metallic glasses, where an atom or group of atoms has two positions close in energy and the conduction electrons are scattered by these centers. $3 /$ In several cases resistivity minima have been observed with logarithmic temperature dependence. These observations invoked the idea of similarity between these systems and Kondo effect in dilute magnetic alloys. $4 /$ In case of the present problem the tunneling motion of the atom is associated with screening by conduction electrons thus it is closely related to the X-ray absorbtion problem. The problem has been attacked by Kondo himself $\frac{5,6 /}{}$ who has shown that if the electron scattering appears exclusively in one scattering channel (e,g., in s-channel) then the repeated screening processes result in scaling behavior in terms of the electron band width cut-off $D$, but no spectacular physical effect could be expected because the problem does not scales into the strong coupling region. $\frac{5,7,9 /}{9}$ The situation is, however, essentially different if those two scattering process, in which the atom of the TLS center does not or does change its position have different non-commutative angulár dependence. First Kondo has pointed out ${ }^{6 /}$ that in this non-cummutative case logarithmic contributions to the electrical resistivity exist even in the leading logarithmic approximation. This result obtained in fourth order in perturbation theory $5,8 /$ Kondo $6 /$ used the argument that there is a similarity between the present problem and the behavior of magnetic impurities in dilute alloys. The role of impurity spin is taken over by the internal degree of freedom of the TLS and spin polarization in the conduction band is substituted by the angular dependence of the screening. The aim of the present paper is to demonstrate this analogy beyond the fourth order in perturbation theory by constructing a simplified model, where the first order scaling equation can be solved and tha analogy becomes obvious. 
The general mode1 $9 /$ can be given as $\mathrm{H}=\mathrm{H}_{0}+\mathrm{H}_{1}$ where

$$
H_{0}=\sum_{\vec{k}} \varepsilon_{k} \alpha_{\vec{k}}^{+} a_{\vec{k}}-\frac{\Delta_{o}}{2} \sigma^{z}+\frac{\Delta_{1}}{2} \sigma^{x}
$$

Here $a_{\vec{k}}$ is the annihilation operator for the conduction electron with energy $\varepsilon_{k}$ and with momentum $\vec{k}$ and the electron spin is not labelled as it does not play any role in the present theory. $\sigma^{z}$ and $\sigma^{x}$ are the Paulf operators acting on the states of the TLS, furthermore, $\Delta_{0}$ and $\Delta_{1}$ are the energy splitting and the intrinsic tunneling rate respectively. It is assumed that $\Delta_{0}$ and $\Delta_{1}$ are negiligable with respect to the other variables as energy $\omega$, temperature $T$ and conduction electron cut-off $D$. The interaction of conduction electrons with the TLS is given as

$$
H_{1}=\sum_{\substack{j=x_{0}, y, z \\ \vec{k}, k^{\prime}}}\left(a_{k^{\prime}}^{+} v_{k^{\prime} k}^{1} a_{k}\right) \sigma^{1}
$$

where $v_{k^{\prime} k}^{i}$ are the coupling constants. In realistic models it is usually assumed that $v_{\mathrm{kk}}^{\mathrm{y}}=0$ for the bare value.

The scaling equation for $v_{k^{\prime} k}^{1}$ can be obtained e.g. by Anderson's "poor man's derivation". $10 /$ Eliminating some part of the phase space by lowering the cutoff $D$ the coupling strengths must be changed in order to keep the scattering amplitude invariant. Using the result of perturbation theory $v_{k^{\prime} k}^{s}(x)=v_{k^{\prime} k}^{s}-21 \rho_{0} \int \frac{d s_{\bar{k}}}{s_{F}} v_{k^{\prime} \bar{k}}^{i} v_{k_{k}}^{j} \varepsilon^{1 j s} \log x$ one gets the scaling equation

$$
\frac{\partial v_{k k^{\prime}}^{s}}{\partial \log x}=21 \rho \circ \frac{d S_{\bar{k}}}{S_{F}}\left(v_{k^{\prime} \bar{k}}^{1}-v_{\bar{k}_{k}}^{j}\right) \varepsilon^{1 j s}
$$

where $x=\frac{D}{|\omega|}$ and $\sigma^{1} \sigma^{j}=1 \varepsilon^{1 j k} \sigma^{k}, \rho_{0}$ is the density of states for conduction electron at the Fermi surface, $\mathrm{ds}_{k} / \mathrm{s}_{\mathrm{F}}$ is the normalized surface element of the 
Fermi surface, thus $\int \mathrm{dS}_{\mathrm{k}} / \mathrm{s}_{\mathrm{F}}=1$. This equation is valid in the leading logarithmic order and results in a term $\log ^{2}|\omega|$ in the expression of the electron inverse 1ifetime obtained in fourth order. $6,11 /$ It is hard to find the scaling trajectories for an arbitrary momentum dependence in $\mathrm{v}_{\mathrm{kk}}^{i}$, because the momentum dependence is strongly modified also due to scaling. In the general case $v_{k^{\prime} k}^{i}$ can be expanded in terms of a complete set of functions $\mathrm{f}_{\alpha}(\mathrm{k})(\alpha=1,2, \ldots)$

$$
v_{k k^{\prime}}^{i}=\sum_{\alpha \beta} f_{\alpha}^{*}(k) v_{\alpha \beta}^{i} f_{\beta}\left(k^{\prime}\right)
$$

where $f_{\alpha}(k)$ depends only on direction of momentum $k$.

We propose a simplified model by retaining only two of these basic functions, which will be labelled as $\alpha=1,2$. In this subspace we must work two by two matrices, thus these matrices can be expanded also in terms of Pau1i matrices, thus

$$
v_{\alpha \beta}^{i}=v_{x}^{i}\left(\sigma_{x}\right)_{\alpha \beta}+v_{y}^{i}\left(\sigma_{y}\right)_{\alpha \beta}+v_{z}^{i}\left(\sigma_{z}\right)_{\alpha \beta}
$$

where the lower indeces are related to the momentum dependence and the upper ones to the TLS, furthermore, the unit matrix is omitted in this expansion, because it commutes with the other terms. Using this notation: given by eq. (5) the scaling equation (3) has the form

$$
-\frac{\partial v_{\gamma}^{s}}{\partial \log x}=-2 \rho_{o} v_{\alpha}^{i} v_{\beta}^{j} \varepsilon^{i j s} \varepsilon_{\alpha \beta \gamma}
$$

In the following we take $V_{\gamma}^{S}$ as the component $\gamma$ of vector $\vec{V}^{S}=\left(V_{x}^{S}, v_{y}^{S}, v_{z}^{S}\right)$ thus e.g.

$\left(\overrightarrow{\mathrm{V}}^{\mathrm{s}} \overrightarrow{\mathrm{V}}^{\mathrm{p}}\right)=\sum_{\alpha}^{\sum_{\alpha}^{\mathrm{s}} \mathrm{V}_{\alpha}^{\mathrm{p}}}$ and $\left(\overrightarrow{\mathrm{V}}^{\mathrm{i}} \overrightarrow{\mathrm{V}}^{\mathrm{j}} \overrightarrow{\mathrm{V}}^{\mathrm{k}}\right)=\varepsilon^{\alpha \beta \gamma} \mathrm{V}_{\alpha}^{\mathrm{i}} \mathrm{V}_{\beta}^{\mathrm{j}} \mathrm{V}_{\gamma}^{\mathrm{k}}$ 
Making use of simple algebra one can see that

$$
\frac{\partial\left(\overrightarrow{\mathrm{V}}^{\mathrm{P}} \overrightarrow{\mathrm{V}}^{\mathrm{s}}\right)}{\partial \log \mathrm{x}}=0 \text { thus }\left(\overrightarrow{\mathrm{V}}^{\mathrm{P}} \overrightarrow{\mathrm{V}}^{\mathrm{s}}\right)=\text { invariant }
$$

for $p \neq s$. Furthermore, one can verify that

$$
\frac{\partial\left|\vec{v}^{\mathrm{p}}\right|^{2}}{\partial \log \mathrm{x}}=-8 \rho_{0}\left(\overrightarrow{\mathrm{v}}^{\mathrm{x}} \overrightarrow{\mathrm{v}} \mathrm{y} \overrightarrow{\mathrm{v}}^{\mathrm{z}}\right)
$$

thus the rate of change of $\left|\mathrm{v}^{\mathrm{P}}\right|^{2}$ is the independent of $\mathrm{p}$. From this follows that In case $\left(\vec{V}^{\mathrm{x}} \overrightarrow{\mathrm{V}}^{\mathrm{y}} \overrightarrow{\mathrm{V}}^{\mathrm{z}}\right)>0$ the vector $\overrightarrow{\mathrm{V}}^{\mathrm{p}}(\mathrm{p}=\mathrm{x}, \mathrm{y}, \mathrm{z})$ increases as $\mathrm{D}$ is decreasing anc? the ratio $\left|\vec{v}^{\mathrm{P}}\right| /\left|\overrightarrow{\mathrm{v}}^{\mathrm{S}}\right| \rightarrow 1$. Furthermore, according eq. (8) $\mathrm{v}^{\mathrm{P}}(\mathrm{p}=\mathrm{x}, \mathrm{y}, \mathrm{z})$ scales to infinity, thus identity (7) means that they tend to become perpendicular.

Using these identities we can construct the scaling trajectories. Let us assume for the physical values that $\vec{V}^{\mathrm{x}}$ and $\overrightarrow{\mathrm{V}}^{\mathrm{z}}$ are finite and $\overrightarrow{\mathrm{V}}^{\mathrm{y}}=0$. Thus, in the first step $\vec{V}^{y}$ is generated in the normal direction of the plane determined by $\vec{V}^{x}$ and $\vec{V}^{z}$. In the further steps $\vec{V}^{x}$ and $\vec{V}^{z}$ remain in the same plane and the direction of $\vec{V}^{\mathrm{y}}$ is not changing. The assumption $(\overrightarrow{\mathrm{V}} \mathrm{x} \overrightarrow{\mathrm{V}} \mathrm{y} \overrightarrow{\mathrm{v}})>0$ made earlier holds automatica11y and $\vec{V}^{\mathrm{x}}$ and $\overrightarrow{\mathrm{V}}^{\mathrm{z}}$ are approaching step by step to their perpendicular positions. In an advanced stage of scaling $\overrightarrow{\mathrm{V}}, \overrightarrow{\mathrm{V}}, \mathrm{\textrm {V }} \overrightarrow{\mathrm{v}}^{\mathrm{Z}}$ can be considered as the approximate edges of a growing but not turning cube. This scaling trajectories are depicted in Fig. 1. One could, furthermore, calculate the correction to the first order scaling eq. (6). Using the argument of Anderson $10 /$ and Fowler $\stackrel{12}{ }$ in a one dimensional problem one can not expect fixed points which are different from zero and infinite. Therefore, the corrections to the scaling of first order might modify the trajectories but the basic feature of the trajectories can not be altered, thus, the corrections can not change the fact that a weak coupling system scales into the infinitety strong region. The system studied here, indeed, can be regarded as a one-dimensional one because we keep 
a finite number of terms in expansion (4), thus, the absolute value of the momentum $\mathrm{k}$ is the only continous variable.

The result obtained are based on the following approximations:

(i) We kept two values of $\alpha$ in expression (4). Working on a realistic system, more functions must be kept, but very likely a few is satisfactory; e.g. in the specific TLS system studied by Kondo ${ }^{4,5 /}$ three angular momentum channels occur $(1=0,1,2$, with $\mathrm{m}=0)$.

(ii) It has been assumed that the variables $|\omega|$ or $\mathrm{T}$ large compared to the parameters of TLS as $\Delta_{0}$ and $\Delta_{1}$ which act 1ike the extermal magnetic field does in the Kondo problem. Thus, the scaling is blocked by $\Delta_{0}$ and $\Delta_{1}$ as soon as D becomes comparable with them. Similiar effect can be caused by the superconducting energy gap.

The general scaling behavior found shows a strong resemblance to the antiferromagnetic Kondo problem. In both cases the origina1 system is scaled to the strong coupling region and that approaches the isotropic case. In order to make it more obvious one can introduce a new linear combination of $\mathrm{f}_{1}$ and $\mathrm{f}_{2}$ or, in other words, one can rotate the coordinate system in the momentum space that the new axis coincide with the asymptotes of the scaling trajectories of $\vec{V}^{x}, \vec{V}^{y}$, and $\vec{V}^{z}$. In the new system on $1 y v_{x}^{x}$ and $v_{y}^{y}$ and $v_{z}^{z}$ are different from zero. In the first order scaling the Hamiltonian near to the infinite fixed point has the form

$$
H_{1}=V \sigma^{i} \int d k_{1} d k_{2} A_{k_{1} \alpha}^{+}\left(\sigma_{i}\right) \beta_{\beta}^{A} k_{2} \beta
$$

where $A_{k \alpha}=\int \frac{d S k}{S_{F}} a_{k} f(\vec{k})$. Furthermore, because $\left(\vec{V}^{x} \vec{V}+\vec{V}^{z}\right)>0$, thus, $v>0$. Indeed, the scaled Hamiltonian near the fixed point has exactly the form of the Kondo Hamiltonian with antiferromagnetic coupling where $\sigma^{i}$ and $\sigma_{i}$ correspond 
to the localized and conduction electron spin respectively. By taking into account the higher order corrections in the scaling equation it may occur that the system does not scale exactly to the Kondo Hamiltonian, however, that can not change the fact that the scaling leads to the strong coupling region. Some modification could be expected rather in the fine structure of the ground state e.g. the asymptotes of vector $\vec{V}^{1}$ might not be perpendicular.

The internal degree of freedom of the TLS system plays the role of the impurity spin. It is crucial that $\mathrm{v}_{\mathrm{kk}^{\prime}}^{\mathrm{x}}, \mathrm{v}_{\mathrm{kk}^{\prime}}^{\mathrm{y}}$, and $\mathrm{v}_{\mathrm{kk}}^{\mathrm{z}}$, are not commuting in the momentum space just like the conduction electron spin operators in the rea1 space. In the Kondo problem at low temperature a resonance or bound state is formed where the impurity spin is compensated by the conduction electrons, while in the present case a strong correlation occurs between the motion of the TLS atom and the angular distribution in the screening electron cloud. It is hard to give a general expression for the Kondo temperature $T_{K}$ where this correlation becomes strong, but assuming that $\overrightarrow{\mathrm{V}}^{\mathrm{x}}$ is perpendicular to $\vec{V}^{\mathrm{z}}$ already at the beginning one obtains for $\left|\overrightarrow{\mathrm{V}}^{\mathrm{z}}\right| \gg\left|\overrightarrow{\mathrm{V}}^{\mathrm{x}}\right|$ that

$$
T_{K}=D\left|\frac{v^{x}}{v^{z}}\right| \frac{1}{v^{z}} \exp \left\{-(\log 4) / v^{z}\right\}
$$

where $v^{i}=\rho_{0}\left|\vec{V}^{i}\right|$ for $i=x, z$. This result is correct in the leading logarithmic approximation and can be silighty changed by taking into account corrections of higher order in the scaling. In the other limit $\left|v^{x}\right| \sim\left|v^{z}\right|$ one obtains $\mathrm{T}_{\mathrm{K}}=\mathrm{D} \exp \left\{-1 / \mathrm{v}^{\mathrm{z}}\right\}$.

Estimating the Kondo temperature we assume that $\mathrm{v}^{\mathrm{x}}$ is due to the conduction electron assisted tunneling and $v^{z}$ is the non-tunneling coupling, which are usually noncommutative $6 /$. The ratio $v^{x} / v^{2}$ can be easily estimated if we assume that the barrier height $\mathrm{V}$ is modified by the potential due to the fluctuation of conduction electron density and calculating the assisted tunneling rate one

* this forrula is the one corrected by $\mathrm{K}$. vladár. 
get $v^{x} / v^{z} \sim d(2 M V)^{1 / 2} \cdot \Delta_{1} / v$ where $M$ is the mass of the tunneling atom." It is reasonable to assume that there are tunneling states for which $v^{x} / v^{2} \sim 10^{-2}-10^{-3} \cdot \ln$ order to get $T_{k} \geq 0.1 \mathrm{~K}$ one must assume that $\mathrm{v}^{2} \geq 0.6$. This value is somewhat larger than the measured one for $\mathrm{Pd}_{0.78} \mathrm{Si}_{0.16} \mathrm{Cu}_{0.06}$ alloy $14 /$ but that can be different for various systems because it is proportional $\frac{3}{6}, 13 /$ to the pseudo potential of the atom, the Fermi momentum and the separation distance of the two states of TLS and the conduction electron density of states at the Fermi energy.

We consider as the main result of the present paper that it has been shown that a coupling between conduction electrons and TLS can result in an angular dependent screening cloud which is strongly correlated with the motion of the TLS. Being aware of the fact that the model treated here is oversimplified, we believe that a more general physical system may behave in a similar manner. $\underline{13 /}$ The appearance of Kondo state in metallic glasses could lead to several consequences. First of all when a metallic glass is cooled down to lower and lower temperature then less and less TLS center behaves like a free TLS. The sound absorbtion must be essentially modified also and the Kondo state must show up in the behavior of glassy metallic superconductors. The Korringa relaxation mechanism for $\mathrm{TLS}^{14 /}$ is expected to be enhanced as the Kondo temperature is approached in a similar way as the electron inverse lifetime is increasing $\frac{11}{6}$ This might be observed by ultrasonic absorption measurements. Finally, we may note, that this treatment is valid for two and three dimensions as well.

The author expresses his gratitude to J. L. Black, B. Golding and J. Sólyom for valuable discussions and to D. Pines for his hospitality in the Physics Department at the University of I1linois.

\footnotetext{
** and $d$ is the width of the potential barrier
} 
REFERENCES

1. P. W. Anderson, B. I. Halperin, and C. M. Varma, Philos. Mag. 25, 1 (1972).

2. W. A. Phillips, J. Low, Temp. Phys. ㄱ, 351 (1972).

3. See for an excellent review J. L. Black to appear in Metallic Glasses edited by H. J. Günthehodt, Springer-Verlag N. Y.

4. R. W. Cochrane, R. Harris, J. 0. Strom-01sen and M. J. Zuckerman, Phys. Rev. Lett. 35, 676 (1975).

5. J. Kondo, Physica 84B, 40 (1976).

6. J. Kondo, Physica 84B, 207 (1976).

7. J. L. B1ack and B. L. Gyorffy, Phys. Rev. Lett. 41, 1595 (1978).

8. A. Zawadowski and $\mathrm{K}$. Vladár to be published.

9. J. Black, B. L. Gyorffy, K. Vladár, and A. Zawadowski to be published.

10. P. W. Anderson, J. Phys. C. $\underline{3}, 2346$ (1970).

11. The expression obtained for the averaged inverse electron life time in Ref. 8 is

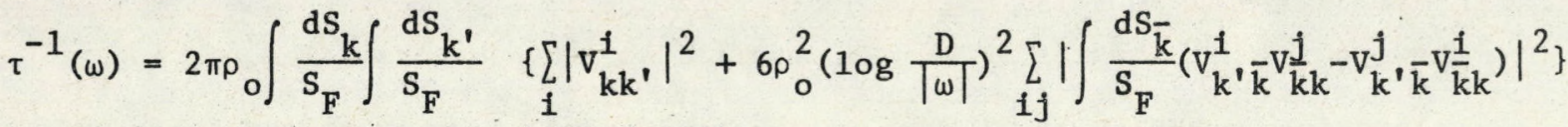

12. M. Fowler, Phys. Rev. 6B, 3422 (1972).

13. J. L. Black, B. L. Gyorffy and J. Jäckle, Phil. Mag B. 40, 331 (1979)

14. B. Golding, J. E. Graebner. A. B. Kane, J. L. Black, Phys. Rev. Lett. 41, 1487 (1978). 


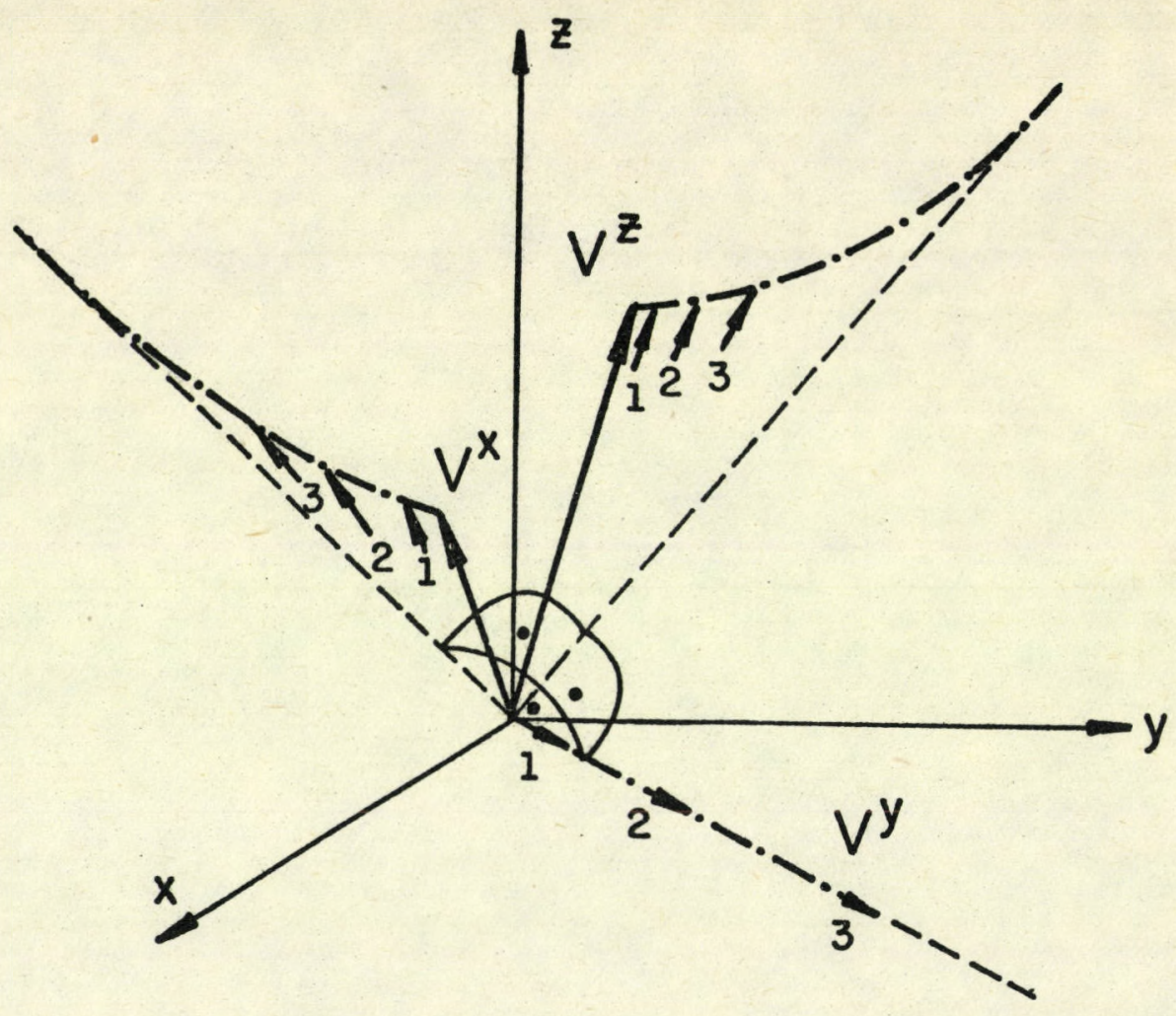

Fig. 1. The scaling trajectories are depicted for eq. 6 in the space variable related to the lower indices. The starting vectors $\vec{v}^{\mathrm{x}}$ and $\overrightarrow{\mathrm{v}}^{\mathrm{z}}$ are shown by solid lines, while $\vec{V}^{\mathrm{y}}$ starts from $\vec{V}^{\mathrm{y}}=0 . \overrightarrow{\mathrm{V}}^{\mathrm{x}}$ and $\overrightarrow{\mathrm{v}}^{\mathrm{z}}$ are scaled in the plane determined by them and $\vec{V}^{y}$ is moving in the normal direction to that plane. The scaling trajectories are depicted by dashed dotted lines, the asymptotes of vectors $\vec{V}^{x}$ and $\vec{V}^{z}$ are represented by dotted 1ines. The arrows indicate the ends of the vectors at different stages of the scaling, which are labelled by numbers. 



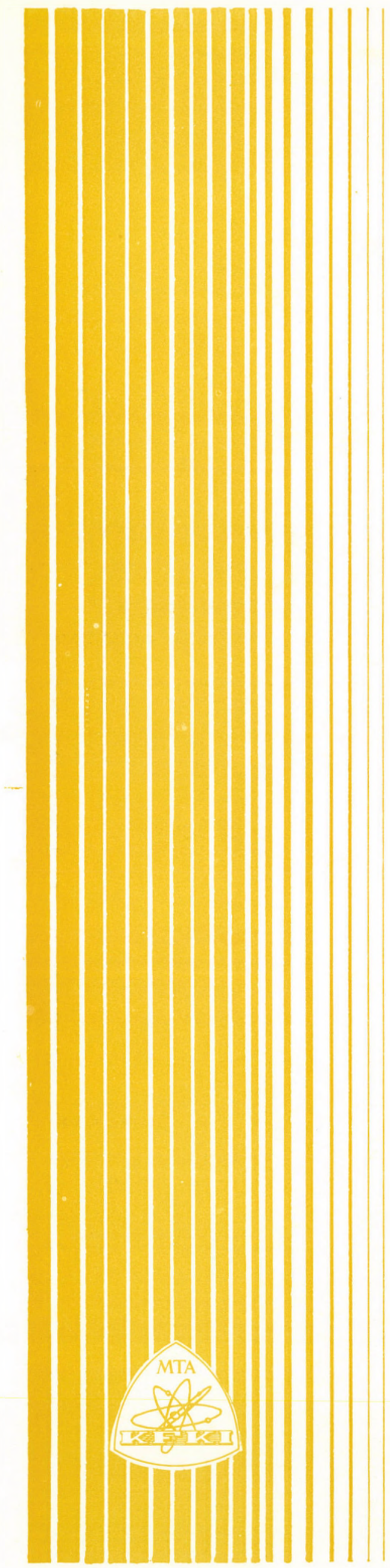

Kiadja a Központi Fizikai Kutató Intézet Felelôs kiadó: Krén Emil

Szakmai lektor: Sólyom Jenõ Nyelvi lektor: Sólyom Jenő

Példányszám: 570 Törzsszám: 80-755 Készült a KFKI sokszorositó üzemében

Felelôs vezetõ: Nagy Károly

Budapest, 1980. december hó 